\title{
Intracranial intradural variations of nerve roots
}

\author{
Kuruc $\mathrm{R}^{1,2}$, Haviarova $\mathrm{Z}^{3}$, Halgas $\mathrm{F}^{4}$, Matejcik $\mathrm{V}^{4}$ \\ Institute of Forensic Medicine, Faculty of Medicine, Comenius University, Bratislava, Slovakia. \\ roman.kuruc77@gmail.com
}

\begin{abstract}
BACKGROUND: The aim of this paper was to point out the intradural cranial nerve roots variations in their localization and number to establish the incidence and clinical importance of the cranial nerve root variations. METHODS: The anatomical study was performed on 120 sides in 60 cadavers. There were 51 male cadavers with the mean age 43.3 and 9 female cadavers with the mean age of 39.5 years.

RESULTS: Abducens nerve variations were observed in 48 cases $(80 \%)$. They were more frequently on the left side, in 25 cases (41.66 \%). Duplicated abducens nerve was observed in 25 cases (41.66\%). Double and triple abducens nerve variations were also observed.

CONCLUSIONS: Cranial nerve variations are rare, but variations of abducens nerve and atypical exit of the hypoglossal nerve from the fossa cranium posterior is not a rare variation. Knowledge of this variation may be important to various fields of medicine (Tab. 3, Fig. 8, Ref. 34). Text in PDF www.elis.sk

KEY WORDS: cranial nerves, abducens nerve, hypoglossal nerve, skull base, anatomical variations.
\end{abstract}

\section{Introduction}

The VI nerve ascends after emerging from the pontomedullary junction and leaves the posterior fossa by piercing the meningeal dura over the clivus approximately $1 \mathrm{~cm}$, inferior and medial to the trigeminal root. Although, in the majority of instances, it is a single nerve exiting through a single dural foramen, there may be more than one fascicle exiting through one or two dural openings.

Development anomalies of the central nervous system are not uncommon. Moreover, they may form the absence of cranial nerve nucleus to cause maldevelopment of a large portion of the brain, and may be associated with defects of other organs. Frequently, development anomalies are not recognized clinically and are unexpectedly found at autopsy (1).

Variant anatomy of the other cranial nerve is very rare. Although it would appear extremely rare, surgeons must consider all variants during head procedures in order to minimize iatrogenic complications (2). Abnormal position involves a great risk of damage (3). Cadaver study demonstrated that knowledge of these variations may be important during a skull base surgery.

${ }^{1}$ Institute of Forensic Medicine, Faculty of Medicine, Comenius University, Bratislava, Slovakia, ${ }^{2}$ Institute of Forensic Medicine, Health Care Surveillance Authority, Bratislava, Slovakia, ${ }^{3}$ Institute of Anatomy, Faculty of Medicine Comenius University, Bratislava, Slovakia, and ${ }^{4}$ Department of Neurosurgery, Faculty of Medicine Comenius University and University Hospital, Bratislava, Slovakia

Address for correspondence: R. Kuruc, MD, PhD, Institute of Forensic Medicine, Faculty of Medicine, Comenius University, Spitalska 24, SK81372 Bratislava, Slovakia.

Phone: +421.2.20856650, Fax: +421.2.20856556
A review of literature revealed cases of the absence of the olfactory bulbs and tracts, of which only $1 / 3$ was not associated with other multiple congenital cerebral anomalies (4). Optic nerve hypoplasia was studied and reported more extensively than aplasia (5). Cranial nerve during its course between the brain stem and cranium usually travels forward as a single trunk, but is not an uncommon variant for the nerve.

Most of the papers on the intracranial variations describe only one of nerve roots as case reports (5-9). Most of the papers deal with describing variations of $n$. abducens (10-15). It is important to know the variations in the course of the abducens nerve and exit of the hypoglossal nerve at the cranial base not only for anatomic knowledge itself, but also for neurosurgical procedures and it may be crucial to avoid iatrogenic surgery. $\mathrm{N}$. accessorius is the second most commonly affected peripheral nerve during a surgery, following median nerve (16).

The submitted paper evaluates the topic of $\mathrm{n}$. abducens.

The anatomical data collected from 60 cadavers represent the basis of the report.

\section{Materials and methods}

The anatomical study was carried out on 120 sides in 60 cadavers within 24 hours from death. There were 51 men (85\%) aged 24-57 years with the mean age 43.3 and 9 women (15\%) aged 20-60 years with the mean age of 39.5 years. The subjects died a violent death, most often in car accidents without skull base fractures.

The calvaria of 60 cadaveric heads were removed by making a horizontal incision from glabella to inion in both sides of the head; after removal of the cranial vault, the dura mater was dissected. 

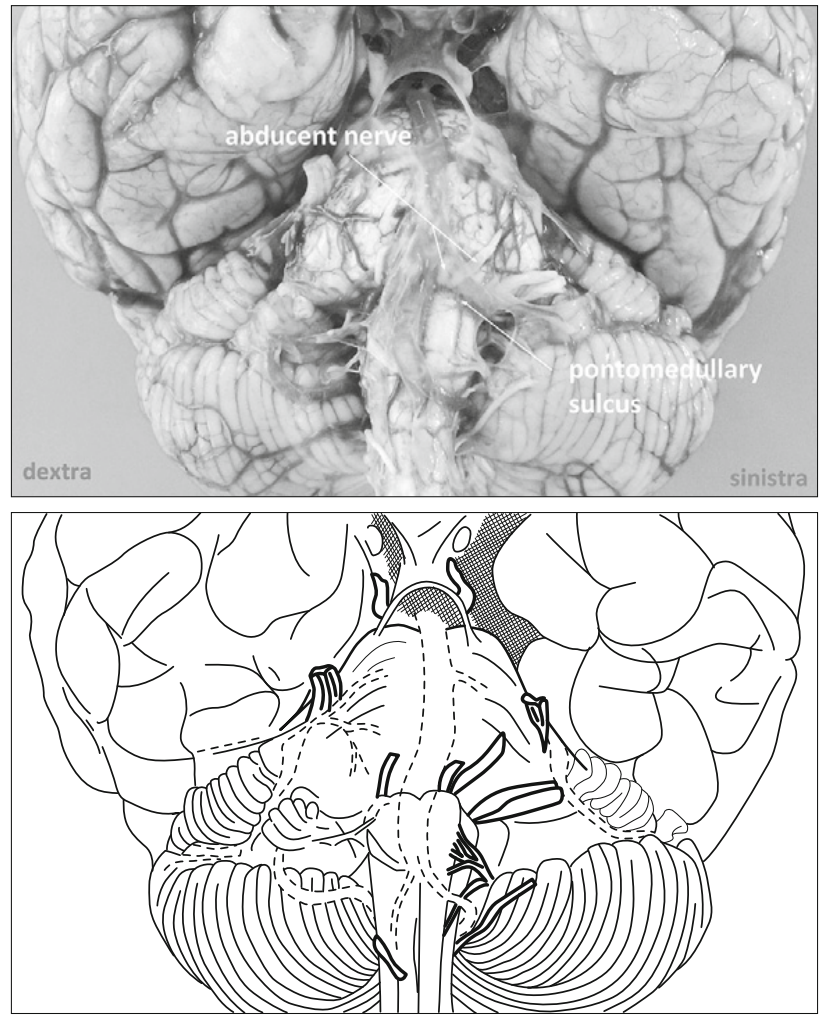

Fig. 1. Front view, double spacing of the abducent nerve l. sin. from the pontomedullary sulcus.
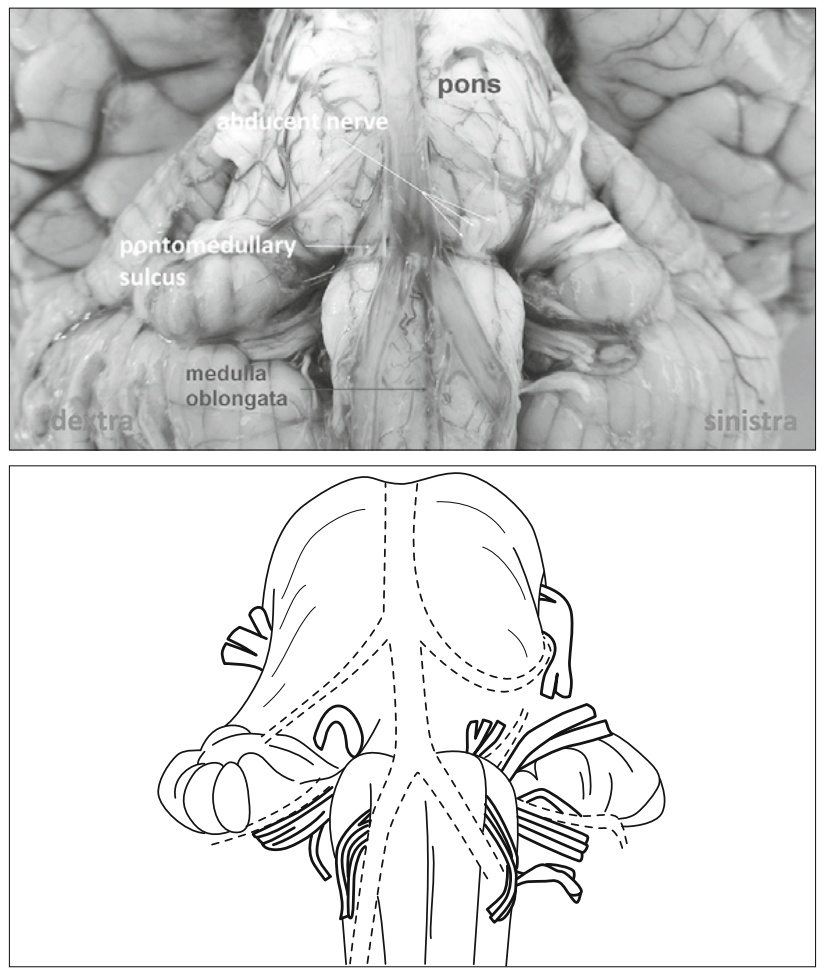

Fig. 2. Front view, triple spacing of the abducent nerve l. sin. from the pontomedullary sulcus.
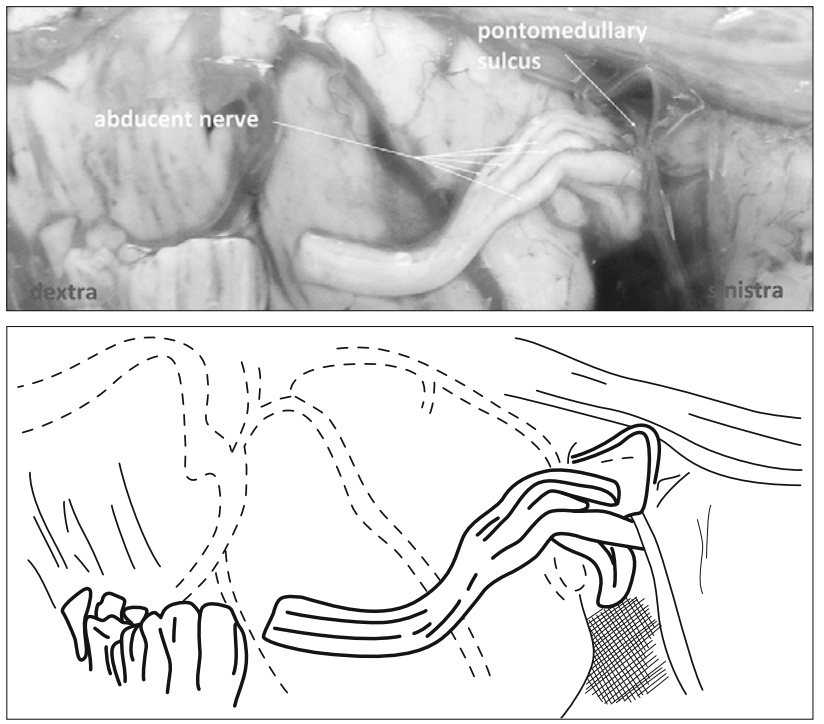

Fig. 3. Front view, more than triple abducent nerve spacing from the pontomedullary sulcus.

Cerebrum and cerebellum were taken out by obtuse dissection of the head. Brain stems were removed with attention paid to the side at which the cranial nerves pierced. The cranial nerves in the right and left side of 60 brain stems and the skull base were examined. The study was conducted with the approval of the ethics committee.

\section{Results}

Abducens nerve variations were observed in 48 cases (80 \%) (Tab. 1). They were more frequently on the left side, in 25 cases (41.66 \%). Duplicated abducens nerve was observed in 25 cases (41.66 \%) (Fig. 1). Eight cases (13.3 \%) had duplicated nerve variations bilaterally. Triple and more abducens nerve variations were observed in 5 cases (8.33 \%) (Figs 2 and 3). Bilateral triple abducens nerve variations were observed in 4 cases (6.66 \%). Coincidental occurrence of double and triple abducens nerve variations were observed in 5 cases (8.33\%). In one case, the absence of one abducens nerve roots was observed (Fig. 4). In 5 cases (8.33\%), the abducens nerve emerged from the brain stem as a single trunk and entered the subarachnoid space, split into two and more branches, and left the fossa cranium posterior through two foramina in 4 cases (6.66 \%). In one case, the abducent nerve trunk split into more than two branches and left the fossa cranium posterior through one foramen.

In 42 cases (70 \%) conversely, the abducens nerve exited the pontomedullary sulcus as two and more separate radices, and after an intradural course of a different length, the nerve roots left the fossa cranium posterior space as a single trunk.

The asymmetry of abducens nerve roots was observed in 7 cases (11.66 \%) (Tab. 2). The atypical exit of the hypoglossal nerve from the fossa cranium posterior was observed in 17 cases 
Tab. 1. Intracranial intradural variations of abducens nerve.

\begin{tabular}{cccccccc}
\hline $\begin{array}{c}\text { Total } \\
\text { number }\end{array}$ & $\begin{array}{c}\text { Number of } \\
\text { variations }\end{array}$ & $\begin{array}{c}\text { Double } \\
\text { spacing }\end{array}$ & $\begin{array}{c}\text { Bilateral } \\
\text { double spacing }\end{array}$ & $\begin{array}{c}\text { Triple } \\
\text { spacing }\end{array}$ & $\begin{array}{c}\text { Bilateral } \\
\text { triple spacing }\end{array}$ & $\begin{array}{c}\text { Coincidental occurrence of } \\
\text { double and triple spacing }\end{array}$ & $\begin{array}{c}\text { Absence of the } \\
\text { abducens nerve roots }\end{array}$ \\
\hline 60 & 48 & 25 & 8 & 5 & 4 & 5 & 1 \\
\hline
\end{tabular}

Tab. 2. Atypical exit of the abducens nerve from the fossa cranium posterior.

\begin{tabular}{cccc}
\hline Total number & $\begin{array}{c}\text { Double abducens nerve trunk } \\
\text { exit through two foramina }\end{array}$ & $\begin{array}{c}\text { Bilateral double abducens nerve } \\
\text { trunk through two foramina }\end{array}$ & $\begin{array}{c}\text { More than double abducens nerve } \\
\text { trunk exit through one foramen }\end{array}$ \\
\hline 5 & 2 & 2 & 1 \\
\hline
\end{tabular}

Tab. 3. Atypical exit of the hypoglossal nerve from the fossa cranium posterior.

\begin{tabular}{ccc}
\hline Total number & $\begin{array}{c}\text { Bilateral exit double hypoglossal nerve trunk } \\
\text { through two foramina }\end{array}$ & $\begin{array}{c}\text { Coincidental occurrence of atypical exit of double abducens } \\
\text { and double hypoglossal nerve through two foramina }\end{array}$ \\
\hline 17 & 13 & 4 \\
\hline
\end{tabular}
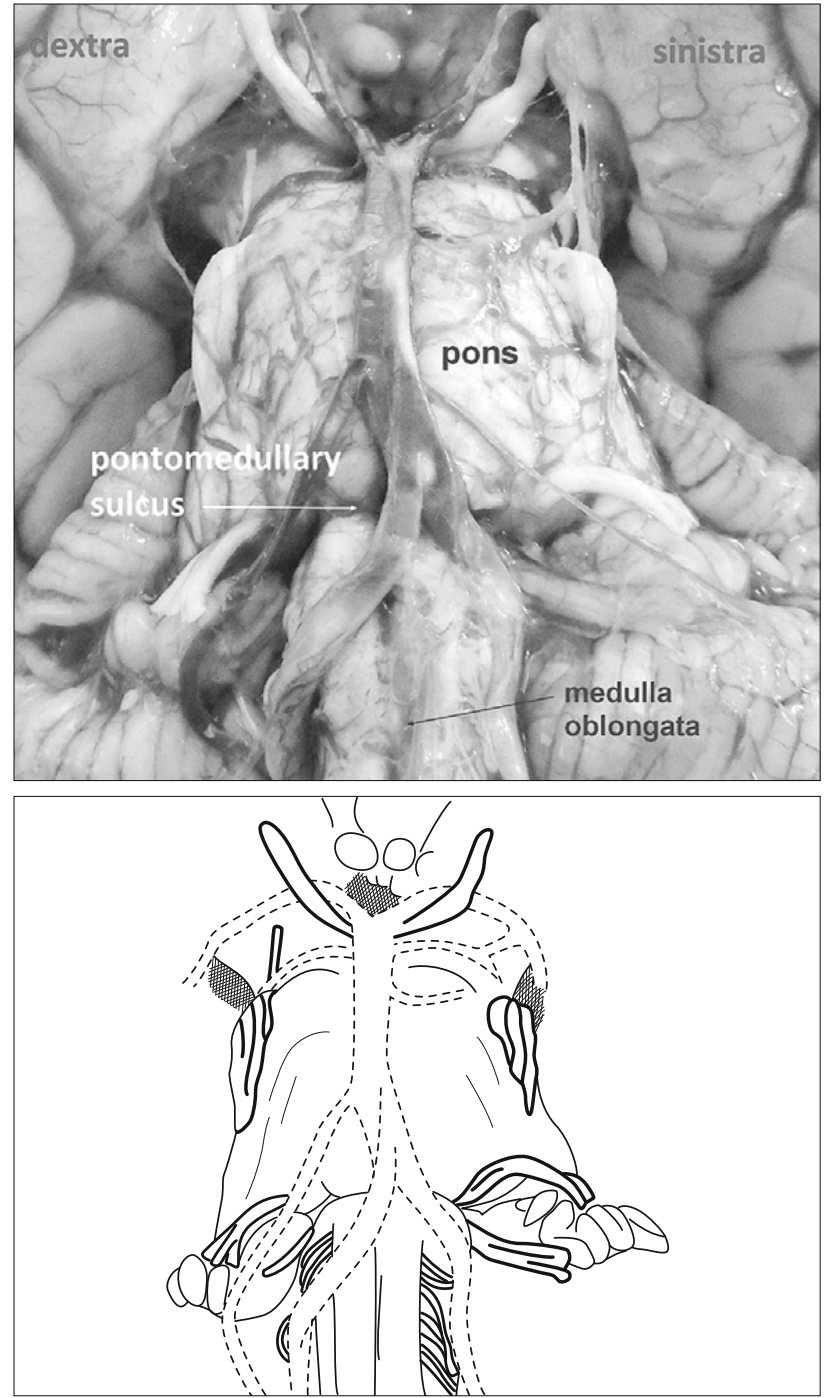

Fig. 4. Pontomedullary sulcus. Front view, absence of the abducent nerve.

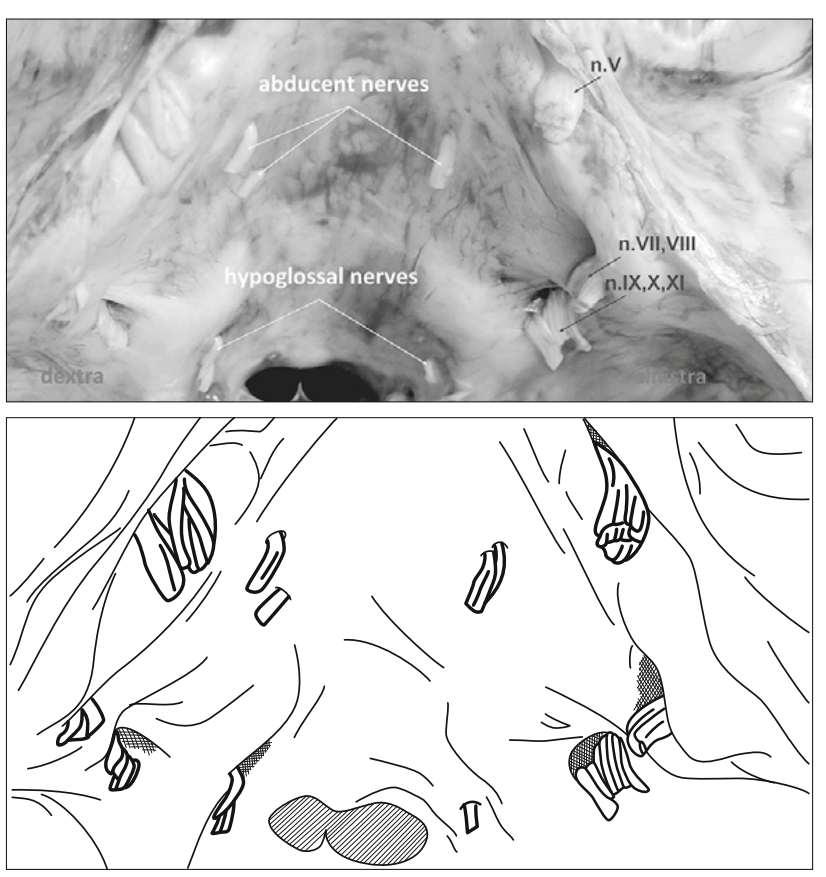

Fig. 5. Dissection of the posterior cranial fossa showing the cranial nerves the abducent and the hypoglossus leaving the cranial cavity through their respective foramina. Back view, coincidental occurrence of atypical spacing, double abducens and double hypoglossal nerve from the fossa cranium posterior through two foramina.

(28.33 \%) (Tab. 3). The nerve roots were separate until they entered the occipital bone.

In 4 cases (6.66 \%), there was an observed coincidental occurrence of atypical exit of double abducens and double hypoglossal nerve from the fossa cranium posterior through two foramina (Figs 5, 6 and 7, Tabs 1 and 2).

Anastomoses between cranial nerve roots were observed in four cases between the glossopharyngeal and vagus nerve. Histological analysis of these connections verified their neural content (Fig. 8). 

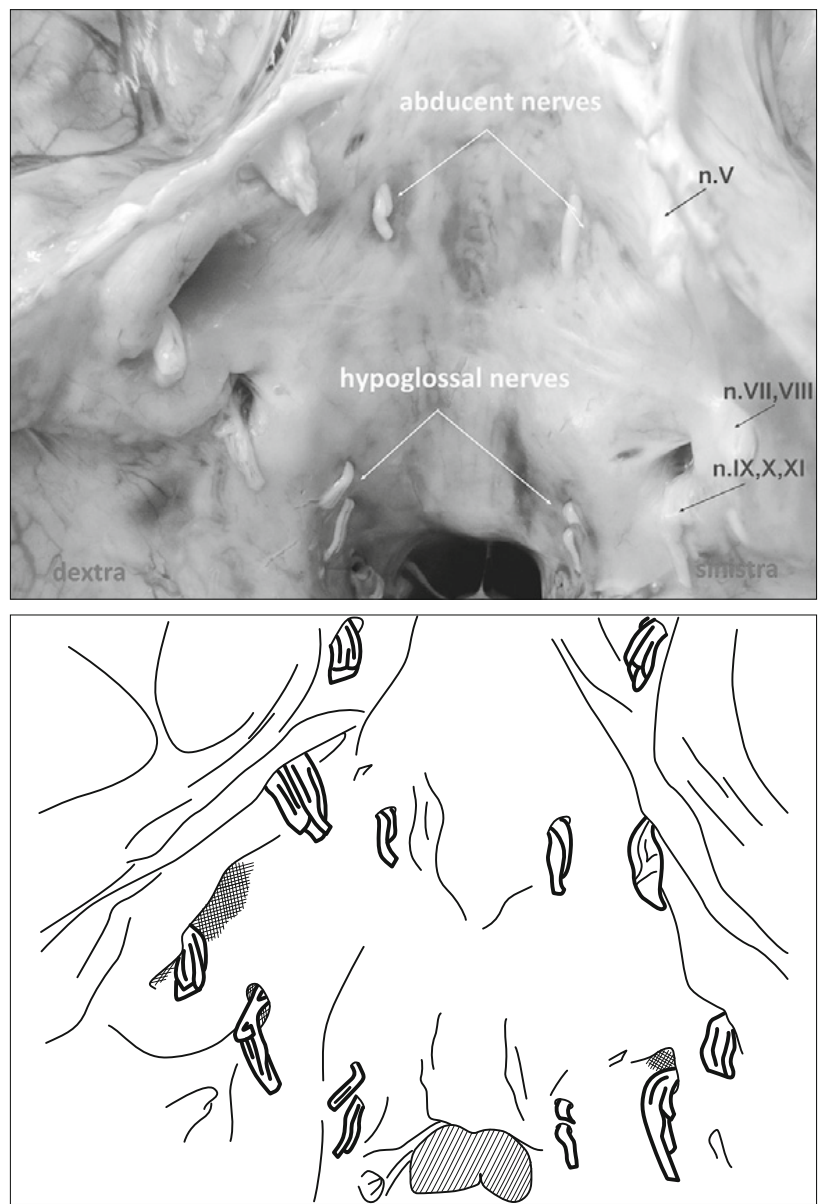

Fig. 6. Dissection of the posterior cranial fossa showing the cranial nerves, the abducent and hypoglossus leaving the cranial cavity through their respective foramina. Back view, coincidental spacing of atypical spacing of the double abducent and double hypoglossal nerves through two foramina.

\section{Discussion}

The sixth cranial nerve is the most commonly affected ocular motor nerve in adults. In children, it is the second most common, following the fourth cranial nerve, with an incidence of 2.5 cases per 100000.

Most papers refer to cranial nerve variations and anomalies as case reports $(1-3,6-8,17-24)$. The aetiology of these variations is unknown. It has to be elucidated.

But variations of abducens nerve are not rare. The incidence of duplicated abducens nerve has been reported to range between 8 and $18 \%$ (10-13). In our study, they occurred in 25 (41.66 \%) cases. Nathan et al (12) did not find any case that had bilaterally duplicated abducens nerve and also reported a case in which the abducens nerve split into three branches. Özveren et al (13) found the incidence of a bilaterally duplicated abducens nerve to be $8 \%$. We observed the occurrence of such disorders in 8 (13.3\%) cases. We observed tripled and more abducens nerve variations in 14 cases (23.33\%). Tillack and Winer (14) reported a case with no
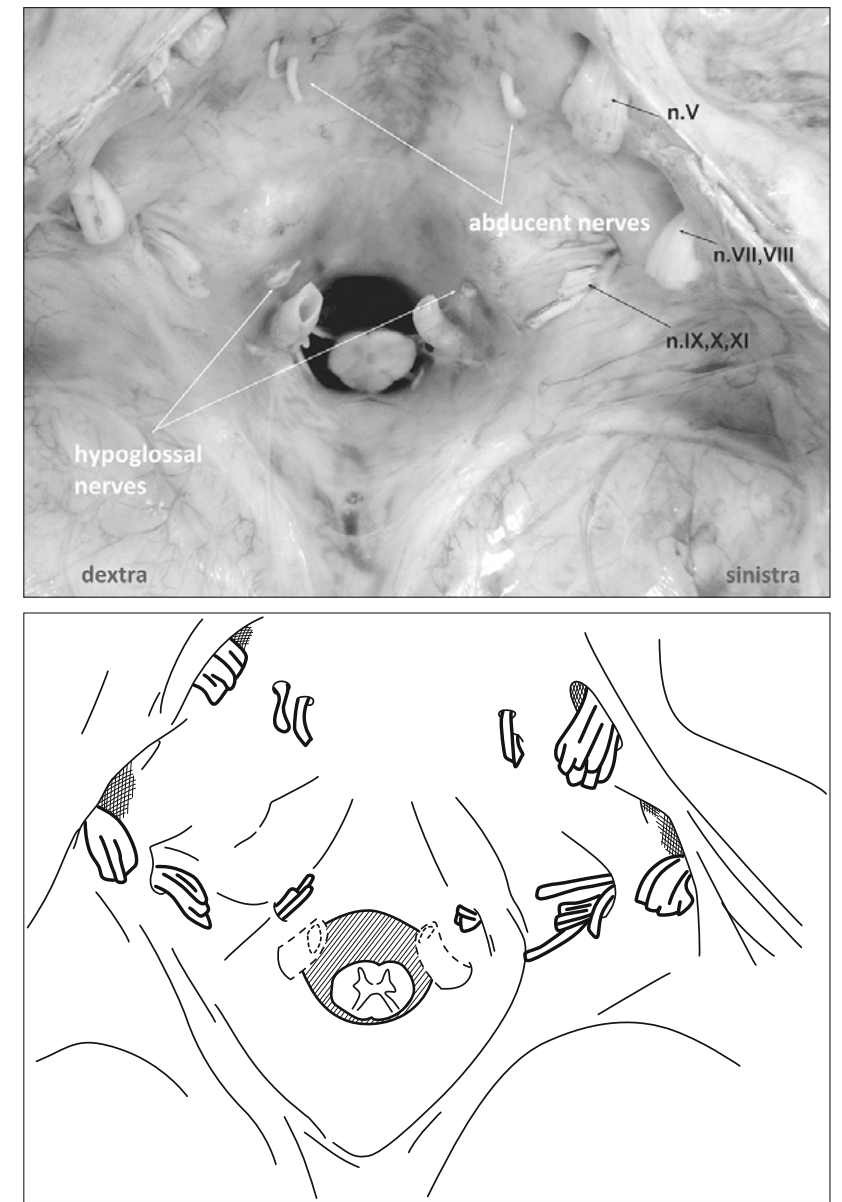

Fig. 7. Dissection of the posterior cranial fossa showing the cranial nerves, the abducent and hypoglossus leaving the cranial cavity through their respective foramina. Back view, coincidental spacing of the double abducent and double hypoglossal nerves through two foramina.

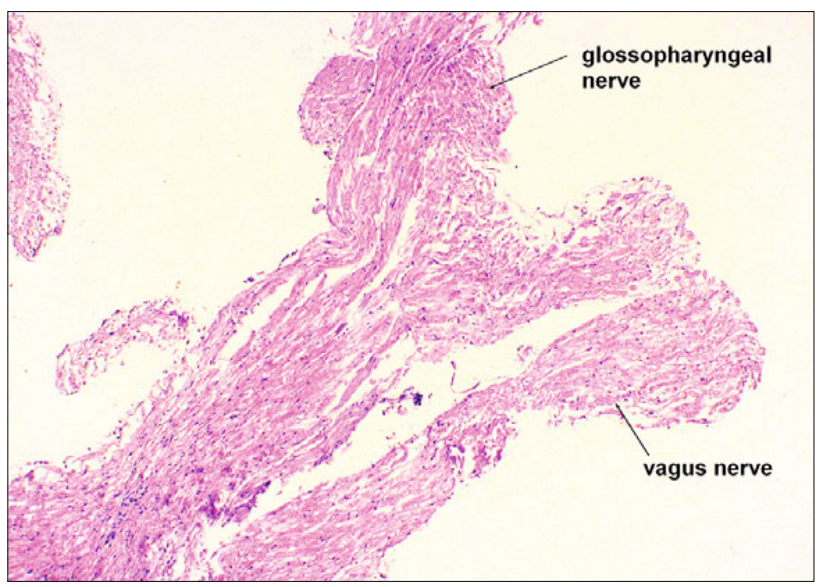

Fig. 8. Intercepted nerve fibres with a thin myelin sheath HE $x$ 40. Anastomoses between nervus vagus and nervus glossopharyngeus. Longitudinal section of the normal arrangement of axons, Schwann cells. 


\section{2-247}

abducens nerve. In our study, also in one case, the absence of one abducens nerve root was observed. In the absence of the abducens nerve, lateral rectus muscle may be supplied by the oculomotor nerve (14). Abducens nerve can pass in the line with the brain stem within the oculomotor nerve (13).

The cases of developmental anomalies are not well known except for those instances in which the mother suffers a definitive infection or toxic disease during pregnancy and thus may affect the embryo or foetus. However, in the majority of cases, a history of a normal pregnancy is obtained, and the case of the maldevelopment is left unexplained $(1,22)$.

The primary defect in optic nerve aplasia and hypoplasia is mesodermal maldevelopment (5). The aetiology of congenital cases, however, remains mostly unidentified (9).

Developing from the ventral lamina of the midbrain, the oculomotor, trochlear, abducens and hypoglossal nerves constitute the somatic efferent group of cranial somites (25). During embryological development, a human embryo is in the form of two aberrant branches $(10,13)$. The absence of the abducens nerve could be explained by the fact that the oculomotor nerve and abducens nerve are members of the somatic efferent groups, so it is not surprising that the abducens nerve travels within the oculomotor nerve (13).

Modern neuroimaging techniques provide improved methods of visualizing cranial nerves. Signal abnormalities within the brain stem and cranial nerves are best visualized with a high resolution T-2 weighted images $(17,24)$.

MR imaging verified the presence of nerve aplasia and demonstrated hemichiasmal hypoplasia on the affected side. MR-A $1 \mathrm{~mm}$-thick slice through the brain stem was acquired with T2 weighted three-dimensional fast spin-echo MRI sequence (17).

Variations of the other cranial nerves are considered to be very rare. However, more and more variations are being recognized by microsurgery (18, 26-30). The incidence of intracranial neural connections between the glossopharyngeal and vagus nerve was $2.5 \%$ (30). We observed it in four cases (6.66 \%). During the formation of the skull, these posterior fossae, no rigid separation of the fibres of the glossopharyngeal, vagus, accessory, and hypoglossal nerves exist. Additionally, the lower cranial nerves merge during development through a common ganglion crest (31). Therefore, it is not surprising that these nerves may communicate along their length.

Specifically (30), any neural connections between the glossopharyngeal and vagus nerve can be sought using a surgical microscope. The functional significance of communicating branches between cranial nerves has never been established, but it is reasonable to suppose that they could hardly present with some purpose of the potential function. Communicating rami are predominantly sensory in function (32).

The intracranial interconnections between lower cranial nerves, especially between the glossopharyngeal and vagus nerve, may be more common because such spinal connections among the cranial nerves may be under-appreciated and missed during the removal of the embalmed brain from the cranial vault.

The hypoglossal nerve shows many variations in its course and branching in the extracranial course, but variations in the cranial cavity are rare (33). The pathological process may cause neuralgia. They may also have a role in essential hypertension and syncope attacks. The vessels are most often their causes. Nayak (34) observed unilateral, double hypoglossal nerves leaving the cranial cavity through two hypoglossal foramina only in one case.

We observed it in 17 cases (28.33\%), when the hypoglossal nerve left the fossa cranium posterior as a single trunk through two foramina.

The two roots of the hypoglossal nerve pierced the dura mater separately and then entered the two hypoglossal canals separately. When they came out of the skull, they had already joined to form the single hypoglossal nerve trunk.

The nerve passing as two roots into the occipital bone and emerging out as one trunk may be of clinical importance.

The nerve roots might get trapped during the ossification process in the occipital bone. If this happens unilaterally or bilaterally, it may result in minor degrees of alterations in movements of the tongue. Though this might not produce any major problems in movement of the tongue, they are good enough to change the quality of the words pronounced by the individual. There are no clinical studies yet on the entrapment of the hypoglossal nerve in the occipital bone. It is worth considering this variation in elderly patients with minor difficulties in movements of the tongue or speech.

Comparing our anatomical findings with the previous results of other authors (10-15, 34), it appears that a percentage rate was higher, and the types of variations were partially different.

Our study was affected by a strong regional focus and a small number of cadavers. This limitation affects the interpretation of our quality and the ability to generalize our findings.

\section{Conclusions}

Cranial nerve variations are extremely rare, but abducens nerve variations and hypoglossal nerve roots exiting from the skull base are not rare. Knowledge of this variation may be important to various fields of medicine.

Although these variations and connections are rare and the significance is unknown, knowledge of them may prove useful to surgeons, who operate in the posterior fossa region so that they may avoid inadvertent traction or transection of these interconnections.

Additionally, such communications might be considered in patients with recalcitrant neuralgia after microvascular decompression and rhizotomy of the cranial nerve.

\section{References}

1. Roback HN, Conway MW. Agenesis of olfactory tracts: report of two cases. Northw Med 1940; 39: 264-265.

2. Islam S, Walton GM, Howe D. Abberant anatomy of the hypoglossal nerve. J Laryngol Otol 2012; 126: 538-540.

3. Greisen O. Aberrant course of the facial nerve. Arch Otolaryngol 1975; 101: 327-328.

4. Petty PG. Absence of olfactory bulbs and tracts with an associated bilobed pineal body. Med J Aust 1965; 2: 492-494. 
5. Hotchkiss ML, Green WR. Optic nerve aplasia and hypoplasia. J Pediatr Ophthalmol Strabismus 1979; 16: 225-240.

6. Biega TJ, Khademian ZP, Vezina G. Isolated absence of the optic chiasm: a rare cause of congenital nystagmus. Am J Neuroradiol 2007; 28: 392-393.

7. Brown MC, Southern CL, Anbarasu A, Kaye SB, Fisher AC, Hagan RP, Newman WD. Congenital absence of optic chiasm: demonstration of an uncrossed visual pathway using monocular flash visual evoked potentials. Doc Ophthalmol 2006; 113: 1-4.

8. Di Rienzo L, Artuso A, Colosimo C. Isolated congenital agenesis of the olfactory bulbs and tracts in a child without Kallmann's syndrome. Ann Otol Rhinol Laryngol 2002; 111: 657-660.

9. Kaeser PF, Kress B, Rohde S, Kolling G. Absence of the fourth cranial nerve in congenital Brown syndrome. Acta Ophthalmol 2012; 90: e310-313.

10. Iaconetta G, Tessitore E, Samii M. Duplicated abducent nerve and its course: microanatomical study and surgery-related considerations. J Neurosurg 2001; 95: 853-858.

11. Jain KK. Aberrant roots of the abducent nerve. J Neurosurg 1954; 21: 349-351.

12. Nathan H, Ouaknine G, Kosary IZ. The abducens nerve. Anatomical variations in its course. J Neurosurg 1974; 41: 561-566.

13. Özveren MF, Sam B, Akdemir I, Alkan A, Tekdemir I, Deda H. Duplication of the abducens nerve at the petroclival region: an anatomic study. Neurosurgery 2003; 52: 645-652.

14. Tillack TW, Winer JA. Anomaly of the abducens nerve. Yale J Biol Med 1962; 34: 620-624.

15. Williams PL, Warwick R. Gray's anatomy. Edinburg, Churchil Livingstone, 1980, ed.36, p. 179 and 1068-1070.

16. Rasulić L, Savić A, Vitošević F, Samardžić M, Živković B, Mićović M, Baščarević V, Puzović V, Joksimović B, Novakovic N, Lepić M, Mandić-Rajčević S. Iatrogenic Peripheral Nerve Injuries-Surgical Treatment and Outcome: 10 Years' Experience. World Neurosurg 2017; 103: 841-851. e6.

17. Chat L, Hertz-Pannier L, Roche O, Boddaert N, Baraton J, Brunelle F. Value of MRI in the diagnosis of unilateral optic nerve aplasia: a case report]. J. Radiol 2002; 83: 1853-1855.

18. Dickinson JT, Srisomboon P, Kamerer DB. Congenital anomaly of the facial nerve. Arch Otolaryngol 1968; 88: 357-359.

19. Jea A, Bașkaya MK, Morcos JJ. Penetration of the optic nerve by an internal carotid artery-ophthalmic artery aneurysm: case report and literature review. Neurosurgery 2003; 53: 996-999.
20. Leek JH. An anomalous facial nerve: the otologist's albatross. Laryngoscope 1974; 84: 1535-1544.

21. Margo CE, Hamed LM, Fang E, Dawson WW. Optic nerve aplasia. Arch Ophthalmol 1992; 110: 1610-1613.

22. Mosin IM, Vasil'eva OI, Pykov MI, Shuleshko OV, Sheianov NG. Isolated aplasia of the optic nerve]. Vestn Oftalmol 2004; 120: 47-51.

23. Scott IU, Warman R, Altman N. Bilateral aplasia of the optic nerves, chiasm, and tracts in an otherwise healthy infant. Am J Ophthalmol 1997; 124: 409-410.

24. Villanueva O, Atkinson DS, Lambert SR. Trigeminal nerve hypoplasia and aplasia in children with goldenhar syndrome and corneal hypoesthesia. J AAPOS 2005; 9: 202-204.

25. Wiliams P, Warwick R. Gray's anatomy. Edinburg, Churchill Livingstone, 1980, ed. 36, p. 174.

26. Kawai K. Terminal distribution of the branch termed Ramus communicans cum nervo glossopharyngeo of the facial nerve and its morphological significance. Acta Anat (Basel) 1995; 153: 57-63.

27. Nageris B, Braverman I, Kalmanowitz M, Segal K, Frenkiel S. Connections of the facial and vestibular nerves: an anatomic study. J Otolaryngol 2000; 29: 159-161.

28. Özveren MF, Türe U, Özek MM, Pamir MN. Anatomic landmarks of the glossopharyngeal nerve: a microsurgical anatomic study. Neurosurgery 2003; 52: 1400-1410.

29. Saraswathi P. Communications between the vagus and hypoglossal nerves. Eur J Anat 2003; 7: 131-134.

30. Tubbs RS, Mortazavi MM, Loukas M, Shoja MM, Cohen-Gadol AA. Intraoperative and anatomical descriptions of intracranial connections between the glossopharyngeal and vagus nerves: clinical implications. J Neurosurg 2011; 115: 179-181.

31. Streeter GL. The development of the cranial and spinal nerves in the occipital region of the human embryo. Am J Anat 1904; 4: 83-116.

32. Baumel JJ. Trigeminal-facial nerve communications. Their function in facial muscle innervation and reinnervation. Arch Otolaryngol 1974; 99: 34-44.

33. BhullerA, Samuoo JR, Chai, D, Abrahams, P.H. Intracranial course and relations of the hypoglossal nerve: an anatomic study. Surg Radiol Anat 1998; 28: 100-112.

34. Nayak SB. Unilateral, double hypoglossal nerves leaving the cranial cavity through two hypoglossal foramina. A case report. Neuroanatomy 2008; 7: 6-7.

Received July 17, 2020. Accepted November 18, 2020. 